\title{
Modified relaxation technique for treating hypertension in Thai postmenopausal women
}

\author{
This article was published in the following Dove Press journal: \\ Journal of Multidisciplinary Healthcare \\ 2 October 2013 \\ Number of times this article has been viewed
}

\author{
Suprawita Saensak ${ }^{1,2}$ \\ Teraporn Vutyavanich ${ }^{3}$ \\ Woraluk Somboonporn ${ }^{4}$ \\ Manit Srisurapanont ${ }^{5}$ \\ 'Academic Department, Faculty \\ of Medicine, Mahasarakham \\ University, Maha Sarakham, Thailand; \\ ${ }^{2}$ Department of Community Medicine, \\ Faculty of Medicine, Chiang Mai \\ University, Thailand; ${ }^{3}$ Department of \\ Obstetrics and Gynecology, Chiang \\ Mai University, Chiang Mai, Thailand; \\ ${ }^{4}$ Department of Obstetrics and \\ Gynecology, Khon Kaen University, \\ Khon Kaen, Thailand; ${ }^{5}$ Department of \\ Psychiatry, Faculty of Medicine, Chiang \\ Mai University, Chiang Mai, Thailand
}

Correspondence: Manit Srisurapanont Department of Psychiatry, Faculty of Medicine, Chiang Mai University,

II 0 Intawarorod Road, Muang,

Chiang Mai 50200, Thailand

Tel +6653945422

Fax +66 53945426

Email manit.s@cmu.ac.th
Aim: To examine the effectiveness of a modified relaxation (MR) technique in reducing blood pressure levels in Thai postmenopausal women with mild hypertension, compared with a control group who received health education.

Methods: This is a 16-week, randomized, parallel, open-label, controlled trial in a menopausal clinic in a tertiary health care center in Northeastern Thailand. The intervention group received a 60-minute session of MR training and were encouraged to practice 15-20 minutes a day, at least 5 days a week. The control group received lifestyle education, including diet and exercise. The primary and secondary outcomes were systolic and diastolic blood pressure (SBP and DBP).

Results: Of 432 participants, 215 and 217 were randomly allocated to the MR and control groups, respectively. Of those, 167 participants in the MR group and 175 participants in the control group completed the study. The SBP was significantly more reduced in the MR group, with a mean of $2.1 \mathrm{mmHg}(P<0.001)$. There was no significant difference between groups on the changed DBP.

Conclusion: The MR technique may be effective in lowering SBP in Thai postmenopausal women visiting a menopause clinic. Its efficacy may be observed as soon as 4 weeks after start of treatment. Long-term and combined relaxation therapy and antihypertensive agents are warranted in a large cohort of this population. This trial is registered in clinicaltrials.gov (number NCT01429662).

Keywords: relaxation, hypertension, postmenopause

\section{Introduction}

Menopause is defined as the permanent cessation of menstrual periods that occurs naturally or is induced by surgery, chemotherapy, or radiation. ${ }^{1,2}$ The menopausal transition concludes with the final menstrual period and the beginning of postmenopause. Despite its clear definition, such a transition may not be recognized until after 12 months of amenorrhea. $^{2}$

Hypertension (HT) (blood pressure [BP] of 140/90 mmHg or higher), especially high systolic BP (SBP), is by far the most important risk factor that affects women in the early postmenopausal years. ${ }^{3}$ Early onset of menopause and a long postmenopausal period are associated with higher BP levels. ${ }^{4-6}$ Menopause increases the risk for HT twofold, even after adjusting for factors such as age and body mass index. ${ }^{7,8}$ The onset of HT can cause a variety of symptoms that are often attributed to menopause., ${ }^{9,10}$ About 30\%-50\% of women develop HT before the age of 60 years. Lowering BP can reduce cardiovascular morbidities and mortality. Reduction of SBP by $5 \mathrm{mmHg}$ can decrease the risk for stroke by $34 \%$ and the risk for ischemic heart disease by $21 \%{ }^{11}$ 
The likelihood of dementia, heart failure, and mortality from cardiovascular disease, is also greatly reduced. ${ }^{11}$

Although antihypertensive medications are the treatment of choice for HT, concerns persist about the potential adverse effects of pharmacologic agents and the necessity for a long-term course of medication. In general practice, the compliance rate for antihypertensive medications may be as low as $81.6 \%$ for patients referred to clinical studies, and $50.6 \%$ for nonreferral cases in general clinics. As an intervention without adverse effects, psychosocial treatment, either alone at the early stage of mild HT, or combined with antihypertensive drugs for moderate/severe HT, should be considered.

Among psychosocial treatments, relaxation therapy is a promising intervention for individuals with HT. Possibly because of its effectiveness in reducing plasma norepinephrine levels and sympathetic nervous system responsivity, this therapy is effective in lowering BP in patients with HT. ${ }^{12-16}$ A 3-month, single-blind, randomized controlled trial was conducted on patients in middle adulthood with HT. ${ }^{17}$ In this sample of 127 African Americans aged 55-70 years, transcendental meditation (TM) and progressive muscle relaxation (PMR) were superior to a lifestyle modification education control program. Although TM reduced SBP by $10.7 \mathrm{mmHg}$ and diastolic blood pressure (DBP) by $6.4 \mathrm{mmHg}$, PMR lowered SBP by $4.7 \mathrm{mmHg}$ and DBP by $3.3 \mathrm{mmHg}$, all of which were significantly higher reductions than those seen in the control group. Compliance was high in both the TM and PMR groups.

To our knowledge, only a community trial of relaxation therapy has been carried out in Asian patients with HT. ${ }^{18}$ In this study, 590 Taiwanese individuals with HT were randomly assigned to have relaxation therapy at home, selflearning packages, or routine BP measurement by a health professional. At 2 months, the SBP of the relaxation therapy group was lowered an average of $11.0 \mathrm{mmHg}$ compared with $5.1 \mathrm{mmHg}$ for the self-learning group.

Relaxation therapy for the treatment of HT is of particular interest for postmenopausal symptoms. Deep breathing, muscle relaxation, guided imagery, body scans, sitting meditation, and mindful stretching may be methods for the self-treatment of hot flashes..$^{19}$ A mindfulness-based stress reduction program also showed that it is effective not only in reducing hot flashes but also in improving the overall quality of life in this population. ${ }^{20}$

The aforementioned evidence suggests that relaxation therapy should be an option for the treatment of HT in postmenopausal women. However, there are limitations to such evidence. First, most studies had several training sessions, which may not be applicable for low-resource health settings. Second, most studies were carried out in Caucasians, who may physically and/or culturally differ from Asians. The only study in Taiwanese people showed only short-term (2-month) benefits of relaxation therapy in individuals with HT living in the community. In this study, we proposed to carry out a medium-term, randomized controlled trial of a modified relaxation (MR) technique to reduce HT in Thai postmenopausal women with mild HT. We included only patients with mild HT because little is known about the efficacy of relaxation therapy for HT, and antihypertensive drug treatment for mild HT is still controversial. ${ }^{21}$

\section{Methods}

This was a 16-week, randomized, parallel, open-label, controlled trial to determine the efficacy of an MR technique in reducing BP in Thai postmenopausal women with mild HT. The study was approved by the Mahasarakham Provincial Hospital ethics committee. After the study detail was fully explained, all participants gave written informed consent before taking part in this trial.

\section{Participants}

This study was carried out at the Menopausal Clinic of Mahasarakham Provincial Hospital, a tertiary health care setting in Northeastern Thailand. The inclusion criteria included postmenopausal women aged 45-65 years who had mild HT (SBP, 140-159 mmHg or DBP, 90-99 mmHg). The exclusion criteria were as follows: using antihypertensive medications, sedatives, tranquilizers, or antidepressants during the previous 2 months before the study; and a language or geographical barrier.

A woman visiting the menopausal clinic would receive medical interviewing, a pelvic examination, and other laboratory tests as required by her attending gynecologist. BP measurement was taken, using the right arm, with a digital sphygmomanometer, using a standardized procedure after the patient sat and rested for 5 minutes. If the first measurement was abnormal, a second one was taken 30 minutes later, and the averages of the two measurements were recorded by a research nurse.

\section{Interventions}

The MR technique was a shortened version of the applied relaxation (AR) technique, provided by a physical therapist, which emphasizes self-practice at home. The AR technique consisted of group instructions 1 hour per 
week for a 12 -week duration. ${ }^{22}$ The AR training generally involves 10-12 sessions and consists of the following components: progressive relaxation; release-only relaxation; cue-controlled relaxation; differential relaxation; rapid relaxation; application training; and maintenance program. The MR technique is a manual, group-based intervention needing only a single 60 -minute training session. The training consists of education on HT in postmenopausal women, breathing training, stretching and releasing muscle tension, and focusing attention on the whole body. Patients were encouraged to practice this MR technique at home 15-20 minutes per day for 5 days a week or more.

The control group received 30 minutes of education and an educational leaflet from a research nurse. The education covered diet, exercise, and smoking/alcohol cessation.

\section{Follow-up assessment}

Both groups received phone calls from the physical therapist or research nurses at $2,4,6,8,10,12$, and 14 weeks to answer any questions relevant to the technique or education, encourage the practice, and for the patients' general wellbeing. All participants visited the clinic at 4, 8, 12, and 16 weeks to have their BP measured, using the same digital sphygmomanometer and procedure.

The primary outcome was the changed SBP. The secondary outcome was the changed DBP.

\section{Sample size}

According to the 3-month study of a 12-session relaxation therapy program for HT in older African Americans, the intervention group had a mean decreased SBP (standard deviation [SD]) of -6.0 (3.0) $\mathrm{mmHg} .{ }^{17}$ Because the MR technique proposed in this study was far less intensive than the 12-session technique, we estimated that the MR technique might decrease SBP (SD) by -1.0 (3.0) mmHg. By setting the alpha level and power of $5 \%$ and $90 \%$, respectively, the sample size needed for this study was 191 patients per group. To compensate for a $15 \%$ dropout rate, the target sample size of this study was, therefore, set at 218 patients per group.

\section{Randomization and blinding}

The allocation ratio for being an intervention participant or a control participant was 1:1. Random allocation sequences at a blocks of 8 were generated by computer. The random number indicating intervention or control was kept in an opaque and sealed envelope. The envelope was opened after the baseline assessment of each participant had been completed. No blindness was applied in this study.

\section{Statistical analysis}

Mean differences between groups on SBP and DBP throughout the study were calculated using multilevel mixed-effect modeling for repeated measures, adjusting for baseline values by entering treatment, time, and baseline values as covariates. The mixed-effect model allowed for random effects on treatment group and time. This assumed there was a population effect for treatment and time but that it varied between individuals. Data were assumed to be missed at random. In addition, a last observation carried forward, intention-to-treat analysis was also conducted to determine the onset of efficacy.

For dichotomous, ordinal, and scale data, the differences between groups were assessed by using chi-square, Mann-Whitney $U(Z)$, and Student's $t$ tests, respectively. A significant difference was set at $P<0.05$ (two-tailed). All analyses were performed using STATA software version 10 (StataCorp LP, College Station, TX, USA).

\section{Results}

This study was carried out between July 2011 and May 2012. Four hundred eighty-eight patients were potential participants. Of these, 432 patients were eligible and randomly allocated to the intervention $(\mathrm{n}=215)$ and control $(\mathrm{n}=217)$ groups, and 167 and 175 patients of the intervention and control groups completed the study, respectively. Dropouts and their reasons for discontinuation are shown in Figure 1.

\section{Demographic and clinical characteristics}

Mean ages (SDs) of the participants were 55.7 (5.2) years for the MR group and 56.2 (5.5) years for the control group. Average age at postmenopause was 48.5 years. There was no significant difference between groups in body mass index and comorbidity of diabetes mellitus. There was, however, a trend of higher SBP and a significantly lower DBP in the MR group (Table 1). All participants were nonsmokers and drank nonalcoholic beverages.

\section{Efficacy}

The data of participants receiving the study interventions and having at least a single assessment at week 4 were included in the analyses ( $n=176$ for the MR group and $n=217$ for the control group). By using a mixed-effect model of the repeated measure analysis, the changed SBP of the MR group during the 16-week period was significantly lower than that of the control group $(P<0.001)$. The intention-to-treat analysis revealed that the significantly lowered SBP could be observed as soon as 4 weeks after the initiation of treatment 


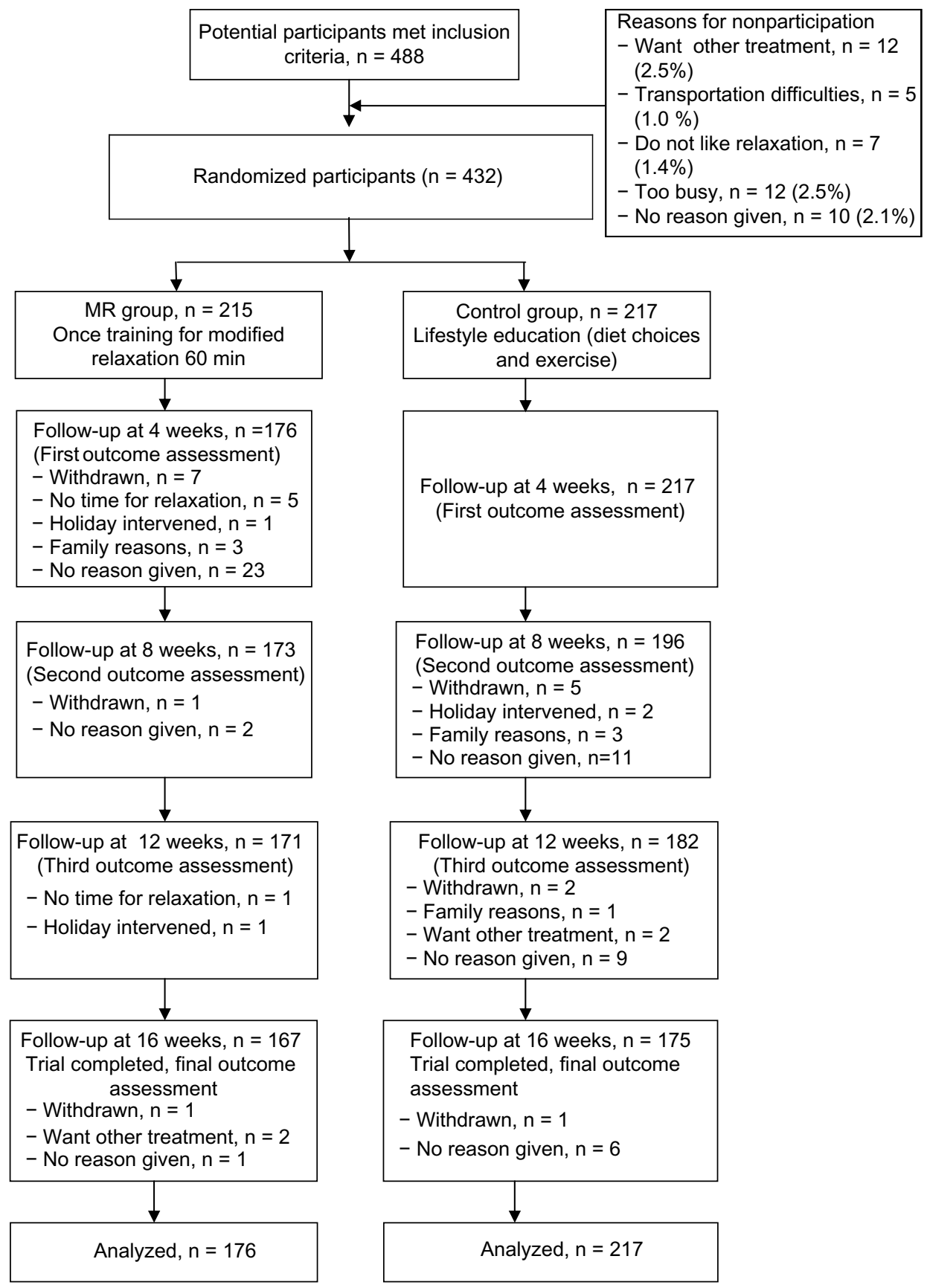

Figure I Patient recruitment and follow-up.

Abbreviation: MR, modified relaxation.

$(P=0.04)$. The changed DBP levels were not significantly different between groups (Table 2).

\section{Discussion}

The MR technique may be effective in lowering SBP in a postmenopausal woman visiting a menopause clinic. Its efficacy may be observed as soon as 4 weeks after start of treatment and last for at least 16 weeks. However, this technique may not be able to lower DBP in this population.
Although the MR technique is a very brief training program, the present findings were in line with previous results showing that relaxation therapy was effective in reducing BP levels in middle-adulthood African Americans and general Asian patients with HT. ${ }^{17,18}$ The changed SBPs $(2.1 \mathrm{mmHg}$ ) found in this trial appeared to be smaller than those of previous studies $(6.0 \mathrm{mmHg})$.

Although the present sample was large enough to detect a small effect size, there were some limitations of this study. 
Table I Demographic characteristics of modified relaxation and control group

\begin{tabular}{|c|c|c|c|}
\hline Characteristics & $\begin{array}{l}M R \\
(n=215)\end{array}$ & $\begin{array}{l}\text { Control } \\
(n=217)\end{array}$ & $\begin{array}{l}\text { Significant } \\
\text { difference }\end{array}$ \\
\hline Age (year) & $55.7(5.2)$ & $56.2(5.5)$ & $\begin{array}{l}t=-1.03 \\
P=0.85\end{array}$ \\
\hline $\begin{array}{l}\text { Age menopause } \\
\text { established (year) }\end{array}$ & $48.6(4.3)$ & $48.4(4.9)$ & $\begin{array}{l}t=0.49 \\
P=0.31\end{array}$ \\
\hline $\begin{array}{l}\text { Body mass index } \\
\left(\mathrm{kg} / \mathrm{m}^{2}\right)\end{array}$ & $25.3(4.3)$ & $26.6(4.2)$ & $\begin{array}{l}t=-3.16 \\
P=0.99\end{array}$ \\
\hline $\begin{array}{l}\text { Diabetes mellitus } \\
\text { (DM) }\end{array}$ & & & $\begin{array}{l}\chi^{2}=3.26 \\
P=0.19\end{array}$ \\
\hline Non-DM & 149 (34.5) & I35 (3I.3) & \\
\hline $\begin{array}{l}\text { DM (insulin } \\
\text { dependent) }\end{array}$ & $5(1.2)$ & $10(2.3)$ & \\
\hline $\begin{array}{l}\text { DM (non-insulin } \\
\text { dependent) }\end{array}$ & $61(14.1)$ & $72(16.7)$ & \\
\hline $\begin{array}{l}\text { Clinical systolic blood } \\
\text { pressure, } \mathrm{mmHg}\end{array}$ & $148.6(6.3)$ & I 47.5 (6.4) & $\begin{array}{l}t=1.71 \\
P=0.09\end{array}$ \\
\hline $\begin{array}{l}\text { Clinical diastolic blood } \\
\text { pressure, } \mathrm{mmHg}\end{array}$ & 88.I (9.9) & $90.5(10.1)$ & $\begin{array}{l}t=-2.36 \\
P=0.02\end{array}$ \\
\hline
\end{tabular}

Notes: Data of age, age at postmenopause, body mass index, clinical systolic blood pressure, and clinical diastolic blood pressure were mean \pm standard deviation. Modified relaxation (MR), control, systolic blood pressure, and diastolic blood pressure were modified relaxation, lifestyle education, systolic blood pressure, and diastolic blood pressure, respectively.

Table 2 Changed systolic blood pressure and diastolic blood pressure from baseline comparison between the modified relaxation and the control groups

\begin{tabular}{|c|c|c|c|c|}
\hline Outcomes & $\begin{array}{l}\text { MR } \\
(n=176)\end{array}$ & $\begin{array}{l}\text { Control } \\
(n=217)\end{array}$ & MEM, RP & ITT \\
\hline $\begin{array}{l}\text { Changed SBP, } \\
\mathrm{mmHg}\end{array}$ & & & $P<0.001$ & \\
\hline 4 weeks & $-4.7 \pm 5.9$ & $-3.4 \pm 6.6$ & & $\begin{array}{l}t=2.04 \\
P=0.04\end{array}$ \\
\hline 8 weeks & $-6.7 \pm 6.9$ & $-5.2 \pm 7.5$ & & $\begin{array}{l}t=2.04 \\
P=0.04\end{array}$ \\
\hline 12 weeks & $-7.9 \pm 5.7$ & $-5.4 \pm 7.8$ & & $\begin{array}{l}t=3.55 \\
P<0.001\end{array}$ \\
\hline 16 weeks & $-8.5 \pm 5.8$ & $-6.4 \pm 7.6$ & & $\begin{array}{l}t=3.02 \\
P=0.002\end{array}$ \\
\hline $\begin{array}{l}\text { Changed DBP, } \\
\mathrm{mmHg}\end{array}$ & & & NS & \\
\hline 4 weeks & $-2.5 \pm 7.2$ & $-3.1 \pm 7.8$ & & $\begin{array}{l}t=0.65 \\
P=0.5 I\end{array}$ \\
\hline 8 weeks & $-4.3 \pm 7.8$ & $-4.8 \pm 10.1$ & & $\begin{array}{l}t=0.32 \\
P=0.75\end{array}$ \\
\hline 12 weeks & $-5.0 \pm 7.9$ & $-4.5 \pm 7.8$ & & $\begin{array}{l}t=0.89 \\
P=0.37\end{array}$ \\
\hline 16 weeks & $-5.2 \pm 7.4$ & $-5.6 \pm 8.3$ & & $\begin{array}{l}t=0.38 \\
P=0.70\end{array}$ \\
\hline
\end{tabular}

Notes: MEM, RP Changed systolic blood pressure and diastolic blood pressure adjusted model by baseline systolic blood pressure, age, and age at postmenopause. Last observation was carried forward of the intention-to-treat analysis.

Abbreviations: MR, modified relaxation; MEM, RP, mixed-effect model for repeated measured analysis; ITT, intention-to-treat analysis; SBP, systolic blood pressure; DBP, diastolic blood pressure; NS, nonsignificant difference.
First, the sample size might be too small to detect the benefit in lowering the DBP, which was usually smaller than that of SBP. ${ }^{18}$ Second, although the applied randomization might reduce the bias toward the participants, the open-label design can still cause a bias toward study treatments. Third, the study duration of 16 weeks might be too short to determine the long-term effects of MR in individuals with HT. However, previous findings suggest that the $2 \mathrm{mmHg}$ of DBP lowered by relaxation therapy might be sustained for a year. ${ }^{23}$ Fourth, the present sample was relatively specific. Although this limitation has been expected since study inception, to be on the safe side, we carried out this study only in postmenopausal women with mild HT. The generalization of these findings to postmenopausal women with moderate or severe HT may not be possible. Fifth, there was no monitoring of adherence to treatments: we could not determine the duration and frequency of MR practice, as well as lifestyle changes in both intervention and control groups. Last, other benefits of MR, eg, the reduction of postmenopausal symptoms, were not assessed.

Despite the aforementioned limitations, the present findings gave another perspective of the MR technique for postmenopausal women with mild HT. A brief (60-minute) training program of relaxation therapy may be helpful in reducing BP levels in this population. Findings of a comprehensive review support that the $2 \mathrm{mmHg}$ reduction of SBP, which was similar to the $2.1 \mathrm{mmHg}$ reduction of SBP found in this study, could significantly reduce the risks for stroke and heart failure. ${ }^{24}$ The results of a Cochrane review also concluded that antihypertensive drugs used in the treatment of otherwise healthy adults with mild HT (SBP, 140-159 mmHg, and/or DBP, 90-99 mmHg) have not been shown to reduce mortality or morbidity in randomized clinical trials. ${ }^{21}$ The conflicting evidence obtained from these two reviews would cause an inconclusive decision on antihypertensive drug treatment but support the role of lifestyle modifications, eg, relaxation therapy, in this population. However, because of the small effect size of treatment $(-2.1 \mathrm{mmHg}$ of $\mathrm{SBP}$ ) in 16 weeks of treatment, it should not be a choice for patients with moderate or severe HT, who need more than $10 \mathrm{mmHg}$ reduction of SBP. It would be of interest to further examine whether this technique would add any benefit to pharmacotherapy of moderate or severe HT in this population (eg, lowering the doses of medications or the reduction of postmenopausal symptoms).

\section{Conclusion}

In conclusion, the MR technique may be effective in lowering SBP in Thai postmenopausal women visiting a 
menopause clinic. Its efficacy may be observed as soon as 4 weeks after treatment was started. Long-term and combined relaxation therapy and antihypertensive agents are warranted in a large cohort of this population.

\section{Acknowledgments}

The authors acknowledge the physiotherapists and professional nurses in Mahasarakham Provincial Hospital who provided the relaxation training and collected data.

\section{Disclosure}

The authors report no conflicts of interest in this work.

\section{References}

1. Peck AC, Chervenak JL, Santoro N. Decisions regarding treatment during the menopause transition. In: Lobo RA, editor. Treatment of the Postmenopausal Woman. 3rd ed. London, United Kingdom: Academic Press; 2007:157-165.

2. National Institutes of Health. NIH State-of-the-Science Conference Statement on Management of Menopause-Related Symptoms. Betheseda: US Department of Health and Human Servies; 2005 Available from: http://consensus.nih.gov/2005/menopausestatement.pdf. Accessed July 1, 2013

3. National Heart, Lung, and Blood Institute [homepage on the Internet]. The Seventh Report of the Joint National Committee on Prevention, Detection, Evaluation, and Treatment of High Blood Pressure; 2004. Available from: http://www.nhlbi.nih.gov/guidelines/hypertension/. Accessed July 1, 2013.

4. Izumi Y, Matsumoto K, Ozawa Y, et al. Effect of age at menopause on blood pressure in postmenopausal women. Am J Hypertens. 2007;20(10): $1045-1050$

5. Mercuro G, Zoncu S, Saiu F, Mascia M, Melis GB, Rosano GM. Menopause induced by oophorectomy reveals a role of ovarian estrogen on the maintenance of pressure homeostasis. Maturitas. 2004;47(2):131-138.

6. Barton M, Meyer MR, Haas E. Hormone replacement therapy and atherosclerosis in postmenopausal women: does aging limit therapeutic benefits? Arterioscler Thromb Vasc Biol. 2007;27(8):1669-1672.

7. Staessen J, Bulpitt CJ, Fagard R, Lijnen P, Amery A. The influence of menopause on blood pressure. J Hum Hypertens. 1989;3(6):427-433.

8. Amigoni S, Morelli P, Parazzini F, Chatenoud L. Determinants of elevated blood pressure in women around menopause: results from a cross-sectional study in Italy. Maturitas. 2000;34(1):25-32.

9. Burt VL, Whelton P, Roccella EJ, et al. Prevalence of hypertension in the US adult population. Results from the Third National Health and Nutrition Examination Survey, 1988-1991. Hypertension. 1995;25(3):305-313.
10. Wassertheil-Smoller S, Anderson G, Psaty BM, et al. Hypertension and its treatment in postmenopausal women: baseline data from the Women's Health Initiative. Hypertension. 2000;36(5):780-789.

11. Law M, Wald N, Morris J. Lowering blood pressure to prevent myocardial infarction and stroke: a new preventive strategy. Health Technol Assess. 2003;7(31):1-94.

12. Lee DD, Kimura S, DeQuattro V, Davison G. Relaxation therapy lowers blood pressure more effectively in hypertensives with raised plasma norepinephrine and blunts pressor response to anger. Clin Exp Hypertens A. 1989;11 Suppl 1:191-198.

13. Hoffman JW, Benson H, Arns PA, et al. Reduced sympathetic nervous system responsivity associated with the relaxation response. Science. 1982;215(4529):190-192.

14. Hjemdahl P, Fagius J, Freyschuss U, et al. Muscle sympathetic activity and norepinephrine release during mental challenge in humans. Am J Physiol. 1989;257(5 Pt 1):E654-E664.

15. Jacob RG, Kraemer HC, Agras WS. Relaxation therapy in the treatment of hypertension. A review. Arch Gen Psychiatry. 1977;34(12): $1417-1427$.

16. Blumenthal JA, Sherwood A, Gullette EC, Georgiades A, Tweedy D. Biobehavioral approaches to the treatment of essential hypertension. J Consult Clin Psychol. 2002;70(3):569-589.

17. Schneider RH, Staggers F, Alxander CN, et al. A randomised controlled trial of stress reduction for hypertension in older African Americans. Hypertension. 1995;26(5):820-827.

18. Yen LL, Patrick WK, Chie WC. Comparison of relaxation techniques, routine blood pressure measurements, and self-learning packages in hypertension control. Prev Med. 1996;25(3):339-345.

19. Fisher TE, Chervenak JL. Lifestyle alterations for the amelioration of hot flashes. Maturitas. 2012;71(3):217-220.

20. Carmody JF, Crawford S, Salmoirago-Blotcher E, Leung K, Churchill L, Olendzki N. Mindfulness training for coping with hot flashes: results of a randomized trial. Menopause. 2011;18(6):611-620.

21. Diao D, Wright JM, Cundiff DK, Gueyffier F. Pharmacotherapy for mild hypertension. Cochrane Database Syst Rev. 2012;8: CD006742.

22. Wijma K, Melin A, Nedstrand E, Hammar M. Treatment of menopausal symptoms with applied relaxation: a pilot study. J Behav Ther Exp Psychiatry. 1997;28(4):251-261.

23. van Montfrans GA, Karemaker JM, Wieling W, Dunning AJ. Relaxation therapy and continuous ambulatory blood pressure in mild hypertension: a controlled study. BMJ. 1990;300(6736):1368-1372.

24. Black HR. The paradigm has shifted to systolic blood pressure. J Hum Hypertens. 2004;18 Suppl 2:S3-S7.
Journal of Multidisciplinary Healthcare

\section{Publish your work in this journal}

The Journal of Multidisciplinary Healthcare is an international, peerreviewed open-access journal that aims to represent and publish research in healthcare areas delivered by practitioners of different disciplines. This includes studies and reviews conducted by multidisciplinary teams as well as research which evaluates the results or conduct of such teams or health-

\section{Dovepress}

care processes in general. The journal covers a wide range of areas and welcomes submission from practitioners at all levels, from all over the world. The manuscript management system is completely online and includes a very quick and fair peer-review system. Visit http://www.dovepress. com/testimonials.php to read real quotes from published authors. 